NASA Technical Memorandum 104459

AIAA-91-1991 )

\title{
Power Electronics for Low Power Arcjets
}

John A. Hamley and Gerald M. Hill Lewis Research Center

Cleveland, Ohio

Prepared for the

27th Joint Propulsion Conference cosponsored by the AIAA, SAE, ASME, and ASEE Sacramento, California, June 24-27, 1991 


\title{
POWER ELECTRONICS FOR LOW POWER ARCJETS
}

John A. Hamley and Gerald M. Hill

National Aeronautics and Space Administration

Lewis Research Center

Cleveland, Ohio 44135

\begin{abstract}
In anticipation of the needs of future light-weight, low-power spacecraft, arcjet power electronics in the 100-400 W operating range were developed. Limited spacecraft power and thermal control capacity of these small spacecraft emphasized the need for high efficiency. Power topologies similar to those in the higher $2 \mathrm{~kW}$ and 5 to $30 \mathrm{~kW}$ power range were implemented, including a four transistor bridge switching circuit, current mode pulse-width modulated control, and an output current averaging inductor with an integral pulse generation winding. Reduction of switching transients was accomplished using a low inductance power distribution network, and no passive snubber circuits were necessary for power switch protection. Phase shift control of the power bridge was accomplished using an improved pulse width modulation to phase shift converter circuit. These features, along with conservative magnetics designs allowed power conversion efficiencies of greater than $92.5 \%$ to be achieved into resistive loads over the entire operating range of the converter. Electromagnetic compatibility requirements were not considered in this work, and control power for the converter was derived from $A C$ mains. Addition of input filters and control power converters would result in an efficiency of on the order of $90 \%$ for a flight unit. Due to the developmental nature of arcjet systems at this power level, the exact nature of the thruster/power processor interface was not quantified. Output regulations and current ripple requirements of 1 and $20 \%$ respectively, as well as starting techniques, were derived from the characteristics of the $2 k W$ system but an open circuit voltage in excess of $175 \mathrm{~V}$ was specified. Arcjet integration tests were performed, resulting in successful starts and stable arcjet operation at power levels as low as 240 watts with simulated hydrazine propellant.
\end{abstract}

\section{INTRODUCTION}

The 1950's and 1960's saw arcjets first considered as an advanced propulsion system. The prime interest of NASA during this time period was planetary missions, and research centered around high powered, high specific impulse arcjets using hydrogen propellant. 1-4 Some successful operation at the 1-2 kW power level was demonstrated with hydrogen propellant with the intent of using these devices in an auxiliary propulsion role. Ammonia was also considered as an alternate propellant. ${ }^{5,6}$ Storable propellants such as hydrazine were also tested, but these efforts met with little success. ${ }^{7}$ A review of these programs was compiled by Wallner and Csika in 1965, and research was limited for a period thereafter. 8

The past decade has seen the re-emergence of the arcjet as an advanced propulsion system, especially in the $1-2 \mathrm{~kW}$ power level, auxiliary propulsion role using hydrazine propellant. Stable operation of these devices has been demonstrated over a wide range of power levels and propellant flow rates with specific impulse values of 450-500 seconds. 9-14
Pulse width modulated (PWM) power supplies with integral starting circuits have been developed in the 1-30 kW power level range and have demonstrated reliable start-up and steady state operation with vortex flow stabilized arcjets. 15-17

A new class of spacecraft is being developed with limited power, low voltage power buses which cannot support the $1-2 \mathrm{~kW}$ class arcjet systems, ${ }^{18,19}$ but may benefit from the addition of advanced propulsion systems. These spacecraft are likely to have maximum power system capacities on the order of $1 \mathrm{~kW}$. This limited power capacity places a premium on PPU efficiency to minimize power losses and heat load on the spacecraft. Techniques such as the use of magnetics with low core and conduction losses, along with power stage designs which minimize parasitic impedances must be employed to minimize the losses. These parasitic impedances would otherwise generate transients that must be damped with passive dissipating components. Additionally, spacecraft electromagnetic compatibility requirements necessitate the use of passive input filters. This combined with the power used for control circuits represents a 
significant $2-5 \%$ fraction of the total system power at this low power level, further emphasizing the need to minimize losses.

The arcjet/power processor interface at these low power levels has not yet been quantified, but extrapolation of previous data 20 indicated that PPU output voltages greater than $150 \mathrm{~V}$ will be required. Output ripple requirements, derived from previous work with higher power arcjets, 15-17 indicated that a larger current averaging inductor in the output of the power processor would be needed because of the lower level of output current.

This paper documents the design process of the PPU, and presents the results of arcjet integration tests.

\section{SYSTEM INTERFACES}

\section{Spacecraft/PPU Interface}

Power distribution systems for lightweight, low power spacecraft are likely to be of the low voltage $28 \mathrm{~V}$ nominal type, with a maximum power rating of $1 \mathrm{~kW} .{ }^{18,19}$ Exact power levels available depend on a large number of factors such as battery system capacity, orbit altitude, and array degradation over time. This resulted in the selection of a power range of $100-400 \mathrm{~W}$ for the propulsion system. Due to the developmental nature of the satellites and the arcjet itself at this power level, large tolerance bands were placed on the input and output characteristics of the PPU to allow flexibility in testing. Thus, the input voltage for this design was $28 \mathrm{~V}$ nominal, with a tolerance of +7 and $-4 \mathrm{~V}$. Isolation of the load from the spacecraft bus was required to conform with common single point grounding schemes. EMI filtering was not designed, as no interface specification was available. The design goal for power conversion efficiency was $93 \%$, which corresponds to a heat load of $22.5 \mathrm{~W}$ at a $300 \mathrm{~W}$ output level, but addition of EMI filter losses and control power requirements on the order of $8 \mathrm{~W}$ will result in an overall efficiency of approximately $90 \%$, resulting in a total heat load of $33 \mathrm{~W}$.

\section{Thruster/PPU Interface}

Due to the developmental nature of the low power arcjet system, the exact characteristics of the arcjet/PPU interface were not quantified at the time of the initial design. It was assumed that the eventual propellant choice would be a storable propellant, most likely hydrazine. Previous work has demonstrated techniques for the reliable start and operation of hydrazine arcjets, $15,16,21$ and these techniques were carried through to this work. However, it was decided that a variable amplitude starting pulse would be of value in characterizing the requirements for reliable starts. The maximum pulse amplitude was specified on the order of $4 \mathrm{kV}$ with a duration of $30 \mu \mathrm{s}$. Steady state ripple requirements were set on the order of $20 \%$ as per previous work. ${ }^{15-17}$

\section{Physical Interfaces}

Packaging the PPU in a flight type enclosure was beyond the scope of this effort. In no way were attempts made to minimize the size or weight of the PPU, as the main design goal was power efficiency.

\section{DESIGN}

The overall schematic for the low power arcjet PPU is presented in Figure 1. The various components will be discussed in the following sections

\section{Topology}

A full bridge was chosen as the power circuit topology for the PPU. This was due to the distinct advantages of this circuit compared to a conventional push pull design which were outlined by Gruber in the development of the $5 \mathrm{~kW}$ arcjet PPU. ${ }^{16}$ One important advantage is that the phase-shifted bridge provides a current path for the dissipation of energy stored in leakage and parasitic inductances. However, this energy is still dissipated in the form of conduction losses in the switches, and care must therefore, be taken to minimize the stored energy.A schematic of the full bridge topology is illustrated in Figure 2. The reference side of the bridge with gate drives $\varnothing 1$ and $\varnothing 2$ are operated at a $50 \%$ duty cycle. The phase shifted gate drives $\varnothing 3$ and $\varnothing 4$ are also $50 \%$ duty cycle drives, but their phase is shifted with respect to the reference side to increase or decrease the current through the primary of the power transformer by varying the time the switches on the diagonals of the bridge are on.

\section{Power Stage}

A diagram of the power stage is shown in Figure 3. The physical layout of the power stage was designed to minimize the loop areas of the power conductors to minimize the parasitic inductances of the power stage. The DC input return was used as a baseplate/heat sink for the power stage and was fabricated from a $6.35 \mathrm{~mm}$ aluminum plate. A $3.5 \mathrm{~mm}$ slot was then milled into the plate to accept a $2.5 \mathrm{~mm}$ aluminum bar which served as the positive input voltage bus. The slot was lined with $1 \mathrm{~mm}$ printed circuit board material, which served as an insulator prior to the installation of the bus bar. The bus bar was installed into the prepared slot using nylon screws, such that the top surface of the installed 
bus bar was flush with the surface of the baseplate. In the case of this power stage, switches Q1-4 were two power MOSFETs in parallel. Switches Q1 and Q3 of Figure 2 were then directly mounted to the bus bar, making the common drain connection A of Figure 2. The pins normally used for the drain connection were moved, because the rear of the TO- 247 transistor package also served as the drain connection.

Connections B and C tied the sources of Q1 and Q3 to the drains of Q2 and Q4 respectively, and were the connection points for the power transformer primary winding. Slots for the transformer bus bars were milled in a fashion similar to that for the positive bus, with an important exception. The sources of Q2 and Q4 had to be connected to the DC return baseplate, thus, when the slots were milled "fingers" of baseplate material were left protruding into the slot directly under the source pins for Q2 and Q4. The source pins were then connected to the base plate. Connections $\mathrm{B}$ and $\mathrm{C}$ of figure 2 were made on the bus bars used for the transformer connection. The gate drive leads for each of the transistors were brought in from the back of the power stage with through holes drilled under each of the gate pins. An area of the base plate was removed to allow for the installation of the Hall effect sensors used to measure the primary current. Bus power was brought into the power stage through a stripline and all filter capacitors were connected to minimize lead lengths and loop areas. This resulted in a power stage with minimized parasitic inductance.

\section{Transformer Design}

A Supermalloy tape wound toroidal core with a tape thickness of $0.025 \mathrm{~mm}$ was selected as the core material for the main power transformer. The selection was made based on a history of use of metallic tape wound cores for flight projects, and its superior durability and heat transfer characteristics compared to ferrites. 22 This material was capable of sustaining a flux density on the order of $0.6 \mathrm{~T}$, but this flux density resulted in a core loss of $4.5 \mathrm{~W} / \mathrm{kg}$ at a switching frequency of $8 \mathrm{kHz}$, which was undesirable. A flux density of $0.2 \mathrm{~T}$ was selected, which reduced the core losses an order of magnitude. This was judged a worthwhile option, since the additional turns required on the transformer added only $3 \%$ more mass, and the increased conduction losses were approximately $1 \mathrm{~W}$. Details of the transformer design are listed in Table 1. The switching frequency of $8 \mathrm{kHz}$ was selected to minimize the switching and core losses.

\section{Controls}

All control circuits and gate drive circuits in this design are supplied power from the 110VAC mains. Conversion of these circuits to 28VDC power input is straightforward, but would reduce the overall efficiency on the order of $3 \%$. The basic control circuit for the PPU illustrated in Figure 4 was the PWM controller described by Gruber for the 1 and $5 \mathrm{~kW}$ arcjet power electronics and is described in detail elsewhere. 15,16 An improved phase shift converter circuit was implemented and is illustrated in figure 5. Operational details of this circuit appear in Appendix A.

The full bridge power stage configuration required isolated gate drive circuits for Q1-Q4. Note that the drives for Q2 and Q4 could have the same reference, but were isolated in this application. Thus, the control circuits were completely isolated from the simulated spacecraft bus. To facilitate this, a gate isolation circuit 23 was used which utilized optical coupling. This eliminated the need for transformer isolation in the gate drives and the problems observed with transformer gate drive circuits, such as slow rise times. A schematic of this gate drive circuit appears in Figure 6.

\section{Output Filter}

Steady state current ripple requirements on the order of $20 \%$, similar to those of previous units, were carried through to this work, The output filter for the PPU was, itself, similar in concept to previous designs. 15,16 However, due to the low DC arc current and the need for continuous current flow, a larger inductance was required. In the case of the $1 \mathrm{~kW}$ unit, the output inductor is typically on the order of $1 \mathrm{mH}$. For this design a $27 \mathrm{mH}$ inductor was used. A molybdenum powder core with a relative permeability of 300 was chosen to minimize the number of turns required and the overall size of the inductor. Details of the design are presented in Table 1. The number of turns required could be reduced by adding an additional core to the present design.

The output filter also had an integral start winding to produce a high voltage pulse which initiated the arc discharge. Details of this starting technique are presented elsewhere. 21 A front panel potentiometer was added which controlled the duration of the charge cycle time of the pulse winding. This resulted in an adjustable pulse amplitude of 0 to $4.2 \mathrm{kV}$, while maintaining the duration of the pulse near $30 \mu \mathrm{s}$. 


\section{PHYSICAL CHARACTERISTICS}

Minimizing the weight and volume of the completed PPU were beyond the scope of this effort. The overall weight of the completed PPU was $7.0 \mathrm{~kg}$, but this weight includes several $110 \mathrm{~V} 60 \mathrm{~Hz}$ supplies used in the control circuits with their associated magnetics which contributed $2.6 \mathrm{~kg}$ to the total weight. Conversion of these circuits to $28 \mathrm{~V}$ input high frequency converters would reduce their weight on the order of $75 \%$. The heaviest components of the PPU were the magnetics, and these could be made smaller, as an oversized diameter core was used for the main power transformer. Reduction of the core diameter would result in a physically smaller transformer, without altering the designed flux density. The overall dimensions of the PPU were $25.4 \mathrm{~cm} 30.4 \mathrm{~cm} \times 19.1 \mathrm{~cm}$. A photograph of the completed prototype PPU appears in Figure 7.

\section{PERFORMANCE}

\section{Output Characteristics}

The operational envelope for the PPU is presented in Figure 8 for a nominal 28V, minimum $24 \mathrm{~V}$ and maximum $35 \mathrm{~V}$ input into a resistive load. The curve was obtained by setting the current control to the maximum value and varying the load resistance. The open circuit voltage was $180 \mathrm{~V}$, and the current limit was $4 \mathrm{~A}$. At this maximum current point, the power supply is not regulating, and the $4 \mathrm{~A}$ output current was set by the current limit setpoint on the primary side of the power transformer. Thus, these limits represented absolute maximums for the PPU, as the maximum designed current rating was $3.5 \mathrm{~A}$. The effect of changing the input voltage was to increase or decrease the open circuit voltage proportionally. The 4A current limit effectively limits output surge current, which protects the thruster during the start transient.

Line regulation data are presented in Table 2. These data indicate line regulation of better than $1 \%$ over the operational input voltage range for three different load conditions. Load regulation was similarly found to be better than $1 \%$.

Figure 9 illustrates a typical family of start pulses generated by the variable amplitude start circuit. The maximum amplitude was in excess of $4 \mathrm{kV}$ with $30 \mu$ s duration. A pulse of $2.8 \mathrm{kV}$ amplitude was used successfully in interface tests indicating that this arrangement had ample energy to start the thruster

\section{Power Stage}

Performance of the low inductance power stage was as expected. The primary voltage and current waveforms are illustrated in Figure 10. Operating conditions were $28 \mathrm{~V}$ input, and the output voltage and current were $123 \mathrm{~V}$ and $3 \mathrm{~A}$, respectively. These values approximated a full output power condition with an arcjet load. The voltage waveform shows negligible overshoot and ringing at turn on. The current waveform does show some ringing at turn on, however, it must be noted that no snubber circuits were in use. These traces did indicate that snubbers were not necessary for transistor protection, however, EMI considerations may require damping of the oscillations in the primary current. The heat sinking capabilities of this power stage were adequate for room temperature, still air operation of the unit at maximum power. This was originally a concern for the high side switches Q1 and Q3 of Figure 3 since only the positive input bus bar was used as a heat sink for these switches. The other switches, Q2 and Q4 were able to use the more massive baseplate as a heat sink.

\section{Efficiency}

Efficiency measurements were made using the following techniques. Input and output currents were measured using shunts that were calibrated with National Bureau of Standards (NBS) traceable equipment. The input, output and current shunt voltages were measured with a calibrated digital voltmeter (DVM). One meter was used to measure all parameters to minimize variations present in multi-instrument procedures. An output current was established into a resistive load, and several minutes were allowed to pass prior to taking any measurements to allow the load and shunt resistors to equilibrate thermally. The input voltage to the PPU was set at the minimum $24 \mathrm{~V}$, nominal $28 \mathrm{~V}$, and maximum $35 \mathrm{~V}$ value at each of three current setpoints.

Results of the efficiency tests are listed in Table 2. Typical efficiencies were in the range of $92.5-92.8 \%$, which corresponds to a spacecraft maximum heat load of approximately $30 \mathrm{~W}$. Table 3 itemizes some of the power losses. The efficiency can be improved somewhat by adding an additional core to the output inductor, thus reducing the number of turns required. Larger diameter conductors can also be employed to reduce conduction losses, especially in the power transformer secondary and the output inductor. Conduction losses could be further reduced by adding additional MOSFETs in parallel in the 
power stage. It is estimated that the addition of $28 \mathrm{~V}$ control circuits and EMI filters for a flight type unit will reduce the overall efficiency to approximately $90 \%$.

\section{THRUSTER INTERFACE TESTS}

Arcjet interface tests were conducted with a prototype low power arcjet. The thruster design was based on the $1 \mathrm{~kW}$ arcjet described in detail elsewhere. 22 In the case of the prototype thruster, the cathode was reduced in diameter from $3.2 \mathrm{~mm}$ to $1.6 \mathrm{~mm}$, and the anode insert was also modified and is illustrated in Figure 11. The constrictor had a diameter of $0.31 \mathrm{~mm}$ and was $0.05 \mathrm{~mm}$ in length. A $30^{\circ}$ half angle was used in the converging side of the nozzle and the diverging half angle was $20^{\circ}$. A conical tip with a half angle of $30^{\circ}$ was used on the cathode, and the electrode gap was set to $0.39 \mathrm{~mm}$. This geometry was tested with various flow rates to determine starting characteristics and stable steady state operating limits. The propellant used was a $1: 2$ stoichiometric mixture of nitrogen and hydrogen to simulate the products of decomposed hydrazine. Cold flow I $\mathrm{I}_{\mathrm{sp}}$ for this geometry was on the order of $118 \mathrm{sec}$.

\section{Thruster Starts}

For initial thruster interface tests, the pulse of Figure 12a was selected. The pulse had a peak amplitude of $2.8 \mathrm{kV}$ and a duration of approximately $30 \mu \mathrm{s}$. This measurement was taken at the thruster terminals on the feedthrough for the vacuum facility and was a reasonable representation of the pulse at the thruster electrodes. The propellant mass flow rate for this pulse was zero.

A breakdown to arc mode is shown in Figure $12 \mathrm{~b}$. For these tests the main converter power was off, which allowed the gas to be broken down without an attempt to transition to an operational mode. The flow rate at this point was was $2.1 \times 10^{-5} \mathrm{~kg} / \mathrm{sec}$. The gas broke down with the pulse amplitude at approximately $2.4 \mathrm{kV}$ and the arc voltage after breakdown was $30-40 \mathrm{~V}$, indicating a normal low mode start. This arc voltage was well below the open circuit voltage of the PPU, thus, transition to normal operation would be possible. The large current spike at breakdown was measured to be $8 \mathrm{~A}$, but of $1 \mu$ s or less duration. This was likely due to energy stored in the parasitic capacitance of the power cable $^{24}$ and in the RC network in the PCU output used for pulse smoothing. The arc current after this spike was measured at $1.5 \mathrm{~A}$. In this instance, the arc extinguished after $40 \mu \mathrm{s}$, which resulted in a large negative di/dt in the output inductor. This caused a second high voltage pulse to appear at the arcjet. In this case the amplitude of the second pulse was $1.6 \mathrm{kV}$. In some cases, as in Figure 12c, a second breakdown occurred.

An arcjet start is illustrated in Figure 12d. In this case, the converter was powered, thus, transition to steady state operation was possible. No thruster damage was noted in any of the thruster starts.

\section{Steady State Operation}

The low power PPU was tested at seven steady state operating conditions with the prototype thruster. Two flow rates, $1.6 \times 10^{-5}$ and $2.1 \times 10^{-5} \mathrm{~kg} / \mathrm{s}$ were used. The thruster always started successfully at either flow rate, and transition to the steady state condition was uneventful. Static impedance data were taken at $2.5,3.0$, and $3.5 \mathrm{~A}$ with stable operation demonstrated at each point. These static impedance data are plotted in Figure 13, and illustrate the standard negative impedance slope characteristics common to hydrazine arcjets. ${ }^{20}$

Steady-state arc voltage and current waveforms are presented in Figure 14. In this case the peak current was $3.2 \mathrm{~A}$, and the minimum was $2.6 \mathrm{~A}$. This resulted in an average arc current of $2.9 \mathrm{~A}$ with a ripple of $0.6 \mathrm{~A}$ peak-topeak amplitude, or $20.7 \%$. The average arc voltage in this case was $105 \mathrm{~V}$, with a peak-topeak ripple amplitude of $10 \mathrm{~V}$. Power levels varied from a minimum of $240 \mathrm{~W}$ to a maximum of $350 \mathrm{~W}$.

Thruster performance is outlined in Table 4 . The maximum specific impulse obtained was $365 \mathrm{~s}$ with a flow rate of $1.6 \times 10^{-5} \mathrm{~kg} / \mathrm{s}$ and input power of $318.5 \mathrm{~W}$ the minimum specific impulse obtained was $306 \mathrm{~s}$. at $237 \mathrm{~W}$ input.

\section{CONCLUSIONS}

A full bridge, phase shifted, pulse width modulated power electronics unit for arcjets in the 200-400W power range was developed and successfully integrated to an arcjet thruster. A topology similar to that in the $5 \mathrm{~kW}$ power range was implemented, including a full bridge switching circuit, current mode pulse width modulated control, and an output current averaging inductor with an integral pulse generation winding. Reduction of switching transients was accomplished using a low inductance power distribution network, and no passive snubber circuits were necessary for power FET protection. Phase shift control of the power bridge was accomplished using an improved 
PWM to phase shift converter circuit. These design features, along with conservative magnetics designs allowed power conversion efficiencies of greater than $92.5 \%$ to be achieved into resistive loads over the entire operating range of the converter. The addition of control power and EMI filtration would reduce the efficiency of a flight unit to $90 \%$, corresponding to a spacecraft heat load of $33 \mathrm{~W}$ for a $300 \mathrm{~W}$ output. Arcjet integration tests were performed with simulated hydrazine propellant. Nondamaging starts and transitions to steady state operation of the thruster/PPU system were repeatedly demonstrated. Specific impulses in the range of $306-365 \mathrm{sec}$. were achieved at efficiencies of $0.40-0.32$ respectively. Arc powers less than $240 \mathrm{~W}$ were achieved.

\section{APPENDIX A}

This appendix discusses the operational details of the pulse width modulation to phase shift converter circuit of Figure 5. The operational logic levels of this circuit were presented in Figure A1. Note that the time scales for the signals are not to scale and were changed to clarify the illustration. The PWM control chip provided three outputs, an oscillator "OSC" which could be used to slave other control chips to the clock of the master controller and two driver signals "A" and "B" used to control the FETs of a push-pull converter.

The signals A and B were already compatible with standard CMOS logic, however, the OSC signal from the controller was not. Conversion to CMOS logic levels was accomplished by comparator U9. It was noted that rising edge of $\mathrm{A}$ or B occurred a few nanoseconds after the falling edge of the OSC signal, so an RC network was added to the input of U9 to lengthen the input pulse. The total duration of the input pulse was 1 $\mu$ s. The output of U9 was used to trigger monostable multivibrator U4B, which generated a uniform $1 \mu$ s pulse. This pulse train was then used to clock toggle flip-flop U1B which generated the drive signals $\varnothing 1$ and $\varnothing_{2}$ for the reference side of the bridge converter. It should be noted that the drive signals for the power FETs are active low. To prevent simultaneous turn on of $\varnothing 1$ and $\varnothing 2$, the clock pulse to the flip-flop was ORed with the outputs, which drove the outputs high while the flip-flop changed state.

Phase shifting was accomplished by generating another pulse train with monostable multivibrator U4A. This multivibrator was triggered with the following signal:
$\overline{\mathrm{TR}}=(\mathrm{A}+\mathrm{B})+\mathrm{OSC}$

which resulted in $\emptyset 3$ and $\emptyset 4$ in phase with $\emptyset 1$ and $\varnothing 2$ respectively if the pulse width of $A$ or $B$ was zero. As the pulse duration of $\mathrm{A}$ or $\mathrm{B}$ increased the phase angle of the signals increased, until the maximum phase angle on the order of 180 degrees was achieved. This pulse train was used in conjunction with the gate signals $\varnothing 1$ and $\emptyset 2$ to drive set/reset cell U1A. This generated the phase shifted drive signals $\varnothing 3$ and $\varnothing 4$. The technique of combining the trigger pulse with the outputs was used here also to prevent simultaneous turn-on of the FETs on the phase shifted side. All gate drives were disabled by the run switch, which also removed the input reference from the control circuit.

\section{REFERENCES}

1. John, R.R., Connors, J.F., and Bennet, S., "Thirty Day Endurance Test of a $30 \mathrm{~kW}$ Arcjet Engine", AIAA Paper 63-274, June 1963.

2. John, R.R., "Thirty Kilowatt Plasmajet Rocket-Engine Development", RAD-TR-64-6, Avco Corp. , Wilmington, MA, NASA CR54044, 1964.

3. Todd J.P., and Sheets, R.E., "Development of a Regeneratively Cooled 30-kW Arcjet Engine", AIAA Journal, Vol. 3, No. 1, Jan. 1965, pp. 122-126.

4. Todd, J.P., "30 kW Arcjet Thruster Research", APL-TDR-64-58, Giannini Scientific Corp., Santa Ana, CA, Mar. 1964. (Avail. NTIS, AD-601534.)

5. Ducati, A.C., Humpal, H., Metzler, J., Muehlberger, E., Todd, J.P., and Waltzer, H., "1-kW Arcjet-Engine System-Performance Test", Journal of Spacecraft and Rockets, Vol. 1, No. 3, May-June 1964, pp. 327-332.

6. Mc Caughey, O.J., Geideman, W.A., Jr., and Mueller, K., "Research and Development of a 2 kW Arc-Jet Thruster", GRC-1646, Plasmadyne Corp., Santa Ana, CA, NASA CR-54035, 1963.

7. Shepard, C.E., and Watson, V.R., "Performance of a Constricted-Arc Discharge in a Supersonic Nozzle", Physico-Chemical Diagnostics of Plasmas, T.P. Anderson, R.W. Springer, and R.C. Warder, Jr., eds., Northwestern University Press, 1964, pp. 261272, AIAA Paper 63-380. 
8. Wallner, L.E., and Csika, J. Jr., "Arc-Jet Thrustor for Space Propulsion", NASA TN D2868, 1965.

9. Nakanishi, S., "Experimental Performance of a 1 Kilowatt Arcjet Thruster", AIAA Paper 85 2033, Oct. 1985, NASA TM-87131.

10. Curran, F.M., and Nakanishi, S., "Low Power dc Arcjet Operation with Hydrogen/Nitrogen Propellant Mixtures," AIAA Paper 86-1505, June 1986, NASA TM-87279.

11. Hardy, T.L., and Curran, F.M., "Low Power dc Arcjet Operation with Hydrogen/Nitrogen/ Ammonia Mixtures", AIAA Paper 87-1948, June 1987, NASA TM-89876.

12. Knowles, S.C., Smith, W.W., Curran, F.M., and Haag, T.W., "Performance Characterization of a Low Power Hydrazine Arcjet", AIAA Paper 87-1057, May 1987.

13. Knowles, S.C., "Arcjet Thruster Research and Technology, Phase I, Final Report". 87-R1175, Rocket Research Co., Redmond, WA, Sept. 1987.

14. Simon, M.A., Knowles, S.C., Curran F.M., and Hardy, T.L., "Low Power Arcjet Life Issues", AIAA Paper 87-1059, May 1987.

15. Gruber, R.P., "Power Electronics for a 1kW Arcjet Thruster", AIAA Paper 86-1507, June 1986. NASA TM-87340.

16. Gruber, R.P., Gott, R.W., and Haag, T.W., "5-kW Arcjet Power Electronics", AIAA Paper 89-2725, July 1989. NASA TM-102108.

17. Wong, S., Britt, E.J., McKracken, K., Lin, R., "Operational Testing of the Power Conditioning Unit for a $30 \mathrm{kWe}$ Arcjet", Eighth Symposium on Space Nuclear Power Systems, Albuquerque, New Mexico, January, 1991.

18. Stella, P.M., "High Performance Arrays for Lightweight Spacecraft", AIAA/DARPA Meeting on Lightweight Satellite Systems, Monterey, California, August 1987.

19. Dunlop, J.D. and Beauchamp, R., "Making Space Nickel/Hydrogen Batteries Lighter and Less Expensive", AIAA/DARPA Meeting on Lightweight Satellite Systems, Monterey, California, August 1987.
20. Hamley, J.A., "Arcjet Load Characteristics", AIAA Paper 90-2579, June 1990, NASA TM103190.

21. Sarmiento, C.J. and Gruber, R.P., "Low Power Arcjet Thruster Pulse Ignition", AIAA Paper 87-1951, June 1987, NASA TM-100123.

22. Knowles, S.C., and Yano, S.E., and Audland, R.S., "Qualification and Lifetesting of a Flight Design Hydrazine Arcjet System", AIAA Paper 90-2576, June 1990

23. Stuart, T.A., King, R.J., and Chen, K., "An Investigation of Full Bridge DC/DC Converters for Arcjet Thrusters", The University of Toledo, Toledo, Ohio, December 1990, NASA CR187046.

24. Biess, J., Private Communication, TRW Inc., Redondo Beach CA, March 1991. 


\begin{tabular}{|c|c|c|c|c|c|}
\hline Device & Core & $\mathrm{N}_{\text {pri }}$ & $\mathrm{N}_{\mathrm{sec}}$ & $\begin{array}{l}\text { Primary } \\
\text { AWG }\end{array}$ & $\begin{array}{c}\text { Secondary } \\
\text { AWG }\end{array}$ \\
\hline Power & $52022-1 F$ & 18 & 110 & 10 & 16 \\
\hline $\begin{array}{l}\text { Output } \\
\text { Inductor }\end{array}$ & $55104(\mathrm{X} 2)$ & 200 & 18 & 16 & 10 \\
\hline
\end{tabular}

\begin{tabular}{|lcccccc|}
\hline Vin, $\mathrm{V}$ & Iin, $\mathrm{A}$ & Vout, $\mathrm{V}$ & Iout, $\mathrm{A}$ & Pin, W & Pout, W & Eff., \% \\
28.0 & 14.02 & 120.1 & 3.02 & 392.6 & 363.4 & 92.6 \\
24.1 & 16.31 & 120.1 & 3.02 & 392.4 & 363.0 & 92.5 \\
35.0 & 11.25 & 120.1 & 3.02 & 393.6 & 362.9 & 92.2 \\
35.1 & 7.66 & 99.4 & 2.50 & 269.1 & 248.9 & 92.5 \\
28.0 & 9.58 & 99.4 & 2.50 & 268.4 & 248.7 & 92.7 \\
24.0 & 11.17 & 99.4 & 2.50 & 268.0 & 248.7 & 92.8 \\
24.2 & 7.12 & 79.7 & 2.01 & 172.3 & 159.9 & 92.8 \\
28.2 & 6.12 & 79.7 & 2.01 & 172.4 & 159.9 & 92.7 \\
35.0 & 4.93 & 79.7 & 2.01 & 172.6 & 159.9 & 92.6 \\
\hline \multicolumn{7}{r}{} \\
\hline
\end{tabular}

\begin{tabular}{|cc|}
\hline Total Losses at 365W output: $29.5 \mathrm{~W}$ & \\
Conduction Losses: & \\
Transformer Primary: & $2.9 \mathrm{~W}$ \\
Power MOSFETs: & $5.5 \mathrm{~W}$ \\
Transformer Secondary: & $1.3 \mathrm{~W}$ \\
Output Inductor: & $3.7 \mathrm{~W}$ \\
Rectifiers: & $\underline{4.3 \mathrm{~W}}$ \\
& $17.7 \mathrm{~W}$ \\
& \\
Core Losses: & $1.5 \mathrm{~W}$ \\
Power Transformer & $10.3 \mathrm{~W}$ \\
Switching and other & \\
\hline Table 3. Measured power losses at 365W output \\
\hline
\end{tabular}

\begin{tabular}{|ccccccc|}
\hline Flow, $\mathrm{kg} / \mathrm{s}$ & $\mathrm{V}_{\mathrm{arc}}, \mathrm{V}$ & $\mathrm{I}_{\mathrm{arc}}, \mathrm{A}$ & $\mathrm{P}_{\mathrm{arc}}, \mathrm{W}$ & $\mathrm{I}_{\mathrm{Sp}}, \mathrm{S}$ & Thrust, $\mathrm{mN}$ & Efficiency \\
$1.60 \times 10^{-5}$ & 91.0 & 3.5 & 318.5 & 365 & 57.2 & 0.32 \\
$1.60 \times 10^{-5}$ & 96.5 & 3.0 & 289.5 & 355 & 55.6 & 0.33 \\
$1.60 \times 10^{-5}$ & 102.2 & 2.5 & 255.5 & 338 & 53.1 & 0.34 \\
$2.12 \times 10^{-5}$ & 100.3 & 3.5 & 351.1 & 358 & 74.5 & 0.37 \\
$2.12 \times 10^{-5}$ & 105.7 & 3.0 & 317.1 & 344 & 71.6 & 0.38 \\
$2.12 \times 10^{-5}$ & 108.5 & 2.5 & 271.3 & 323 & 67.2 & 0.39 \\
$2.12 \times 10^{-5}$ & 118.4 & 2.0 & 236.8 & 306 & 63.8 & 0.40 \\
\hline \multicolumn{7}{c}{} \\
\hline \multicolumn{7}{c}{ Table 4. Thruster performance at various power levels and mass flow rates } \\
\hline
\end{tabular}




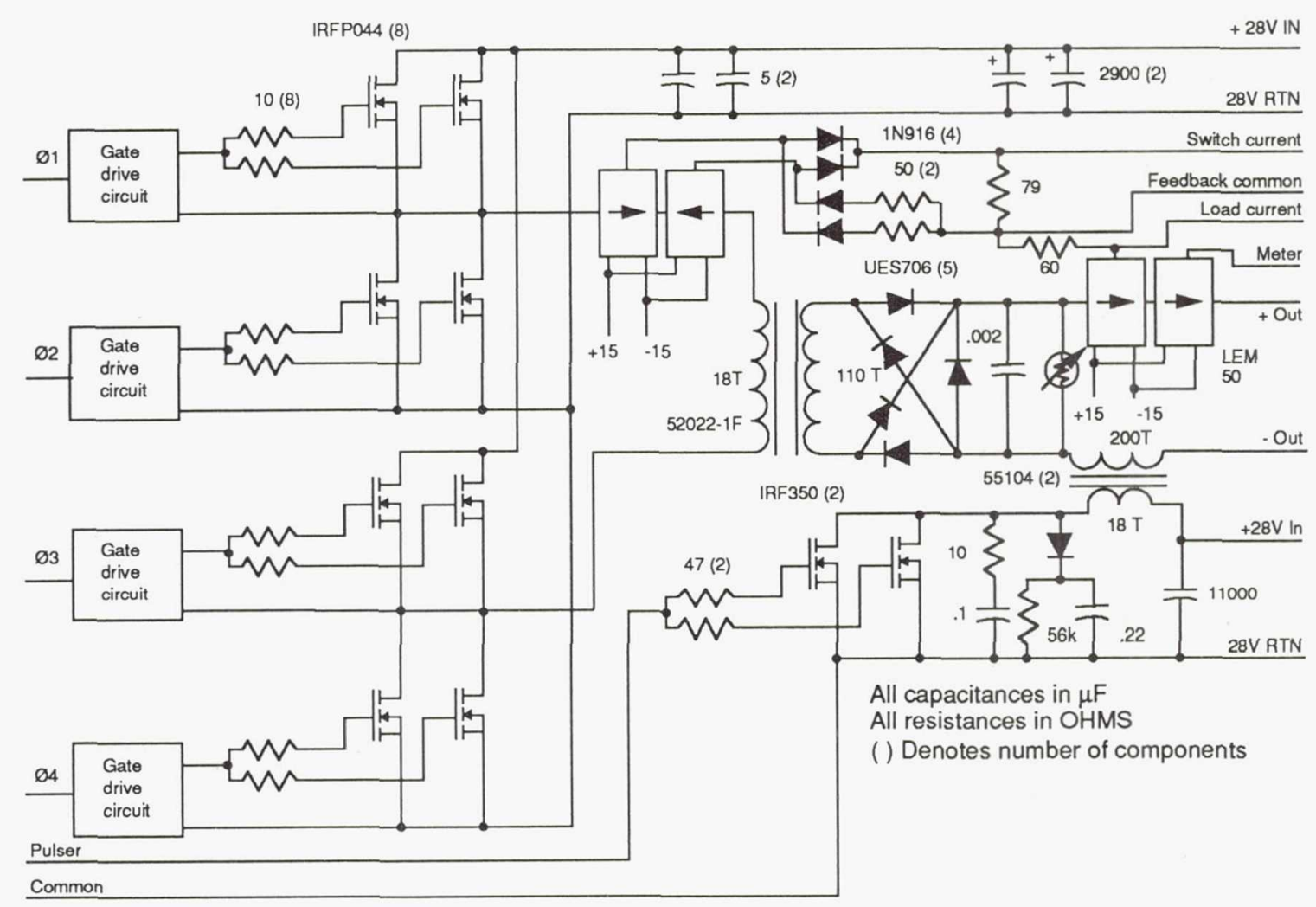

Figure 1.-Low Power Arcjet PPU schematic.

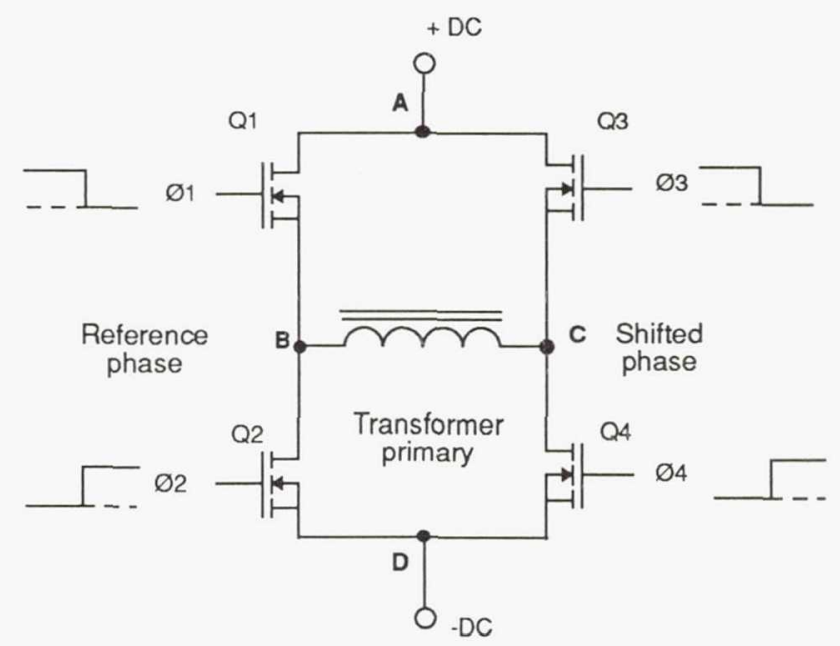

Figure 2.-Full bridge converter topology with phase shifted control. Gate drive signals $\varnothing 1-\varnothing 4$ are shown for zero output condition. 


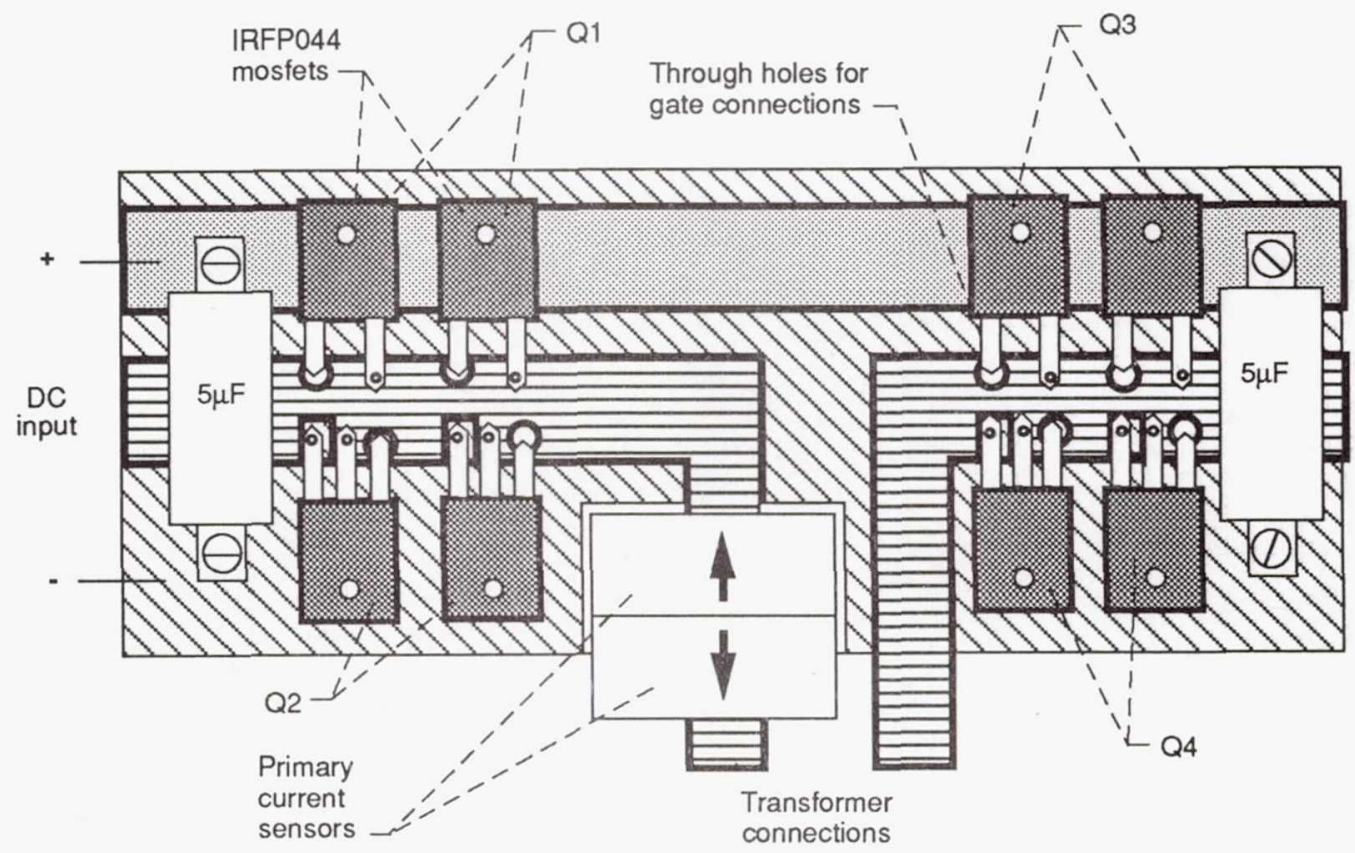

Figure 3.-Low inductance power stage.

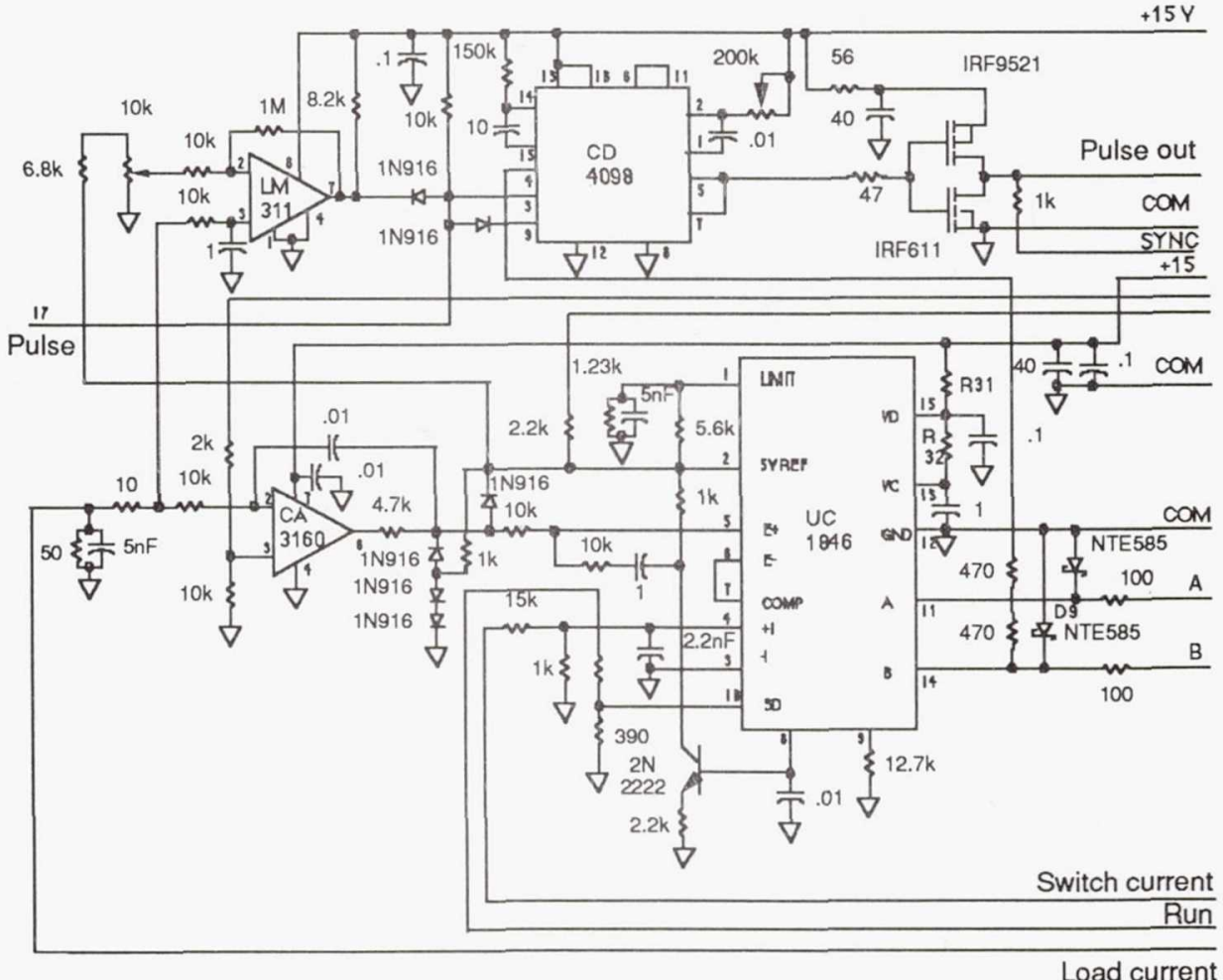

Figure 4.-PWM control circuit (ref. 15). 


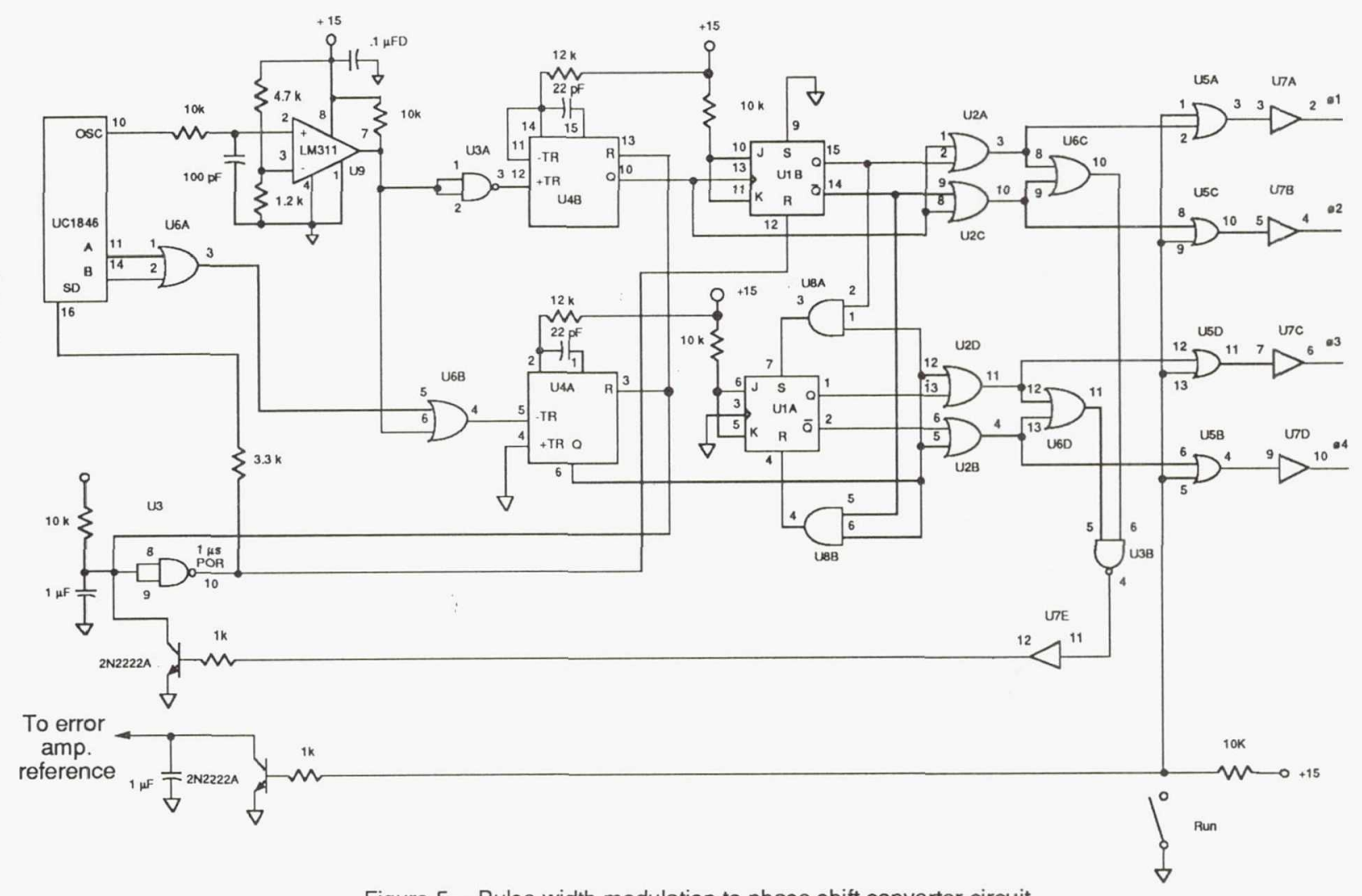

Figure 5.-Pulse width modulation to phase shift converter circuit.

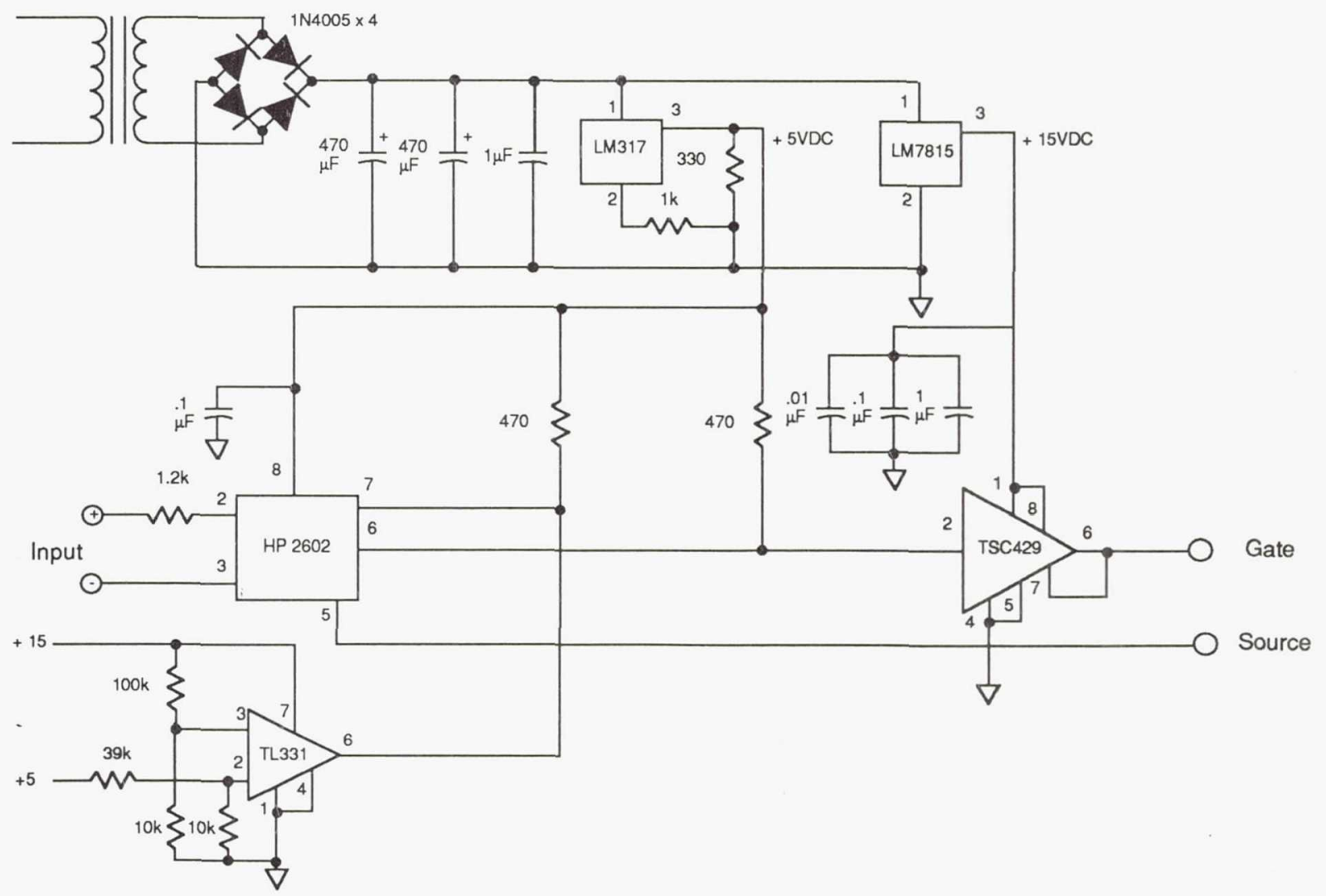

Figure 6.-Isolated gate drive circuit developed by Stuart et. al. (ref. 23). 


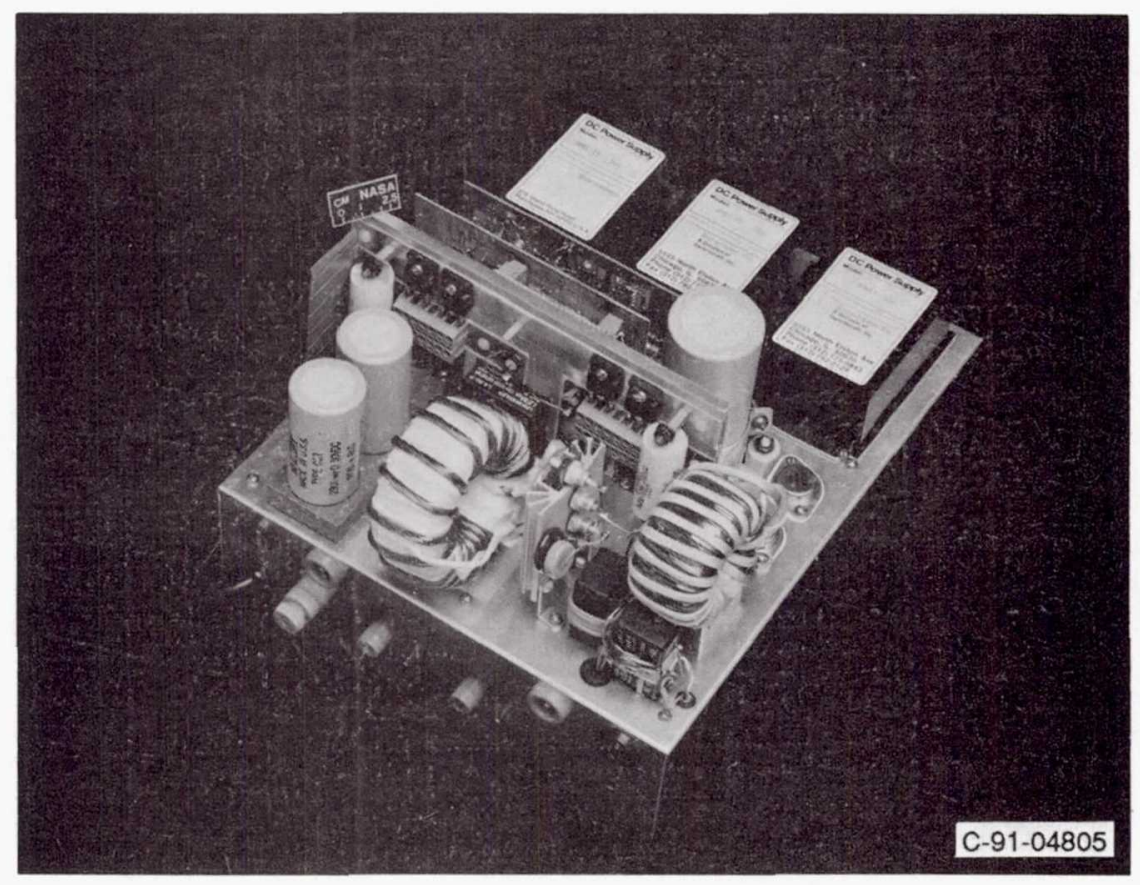

Figure 7.- Photograph of completed power processor.

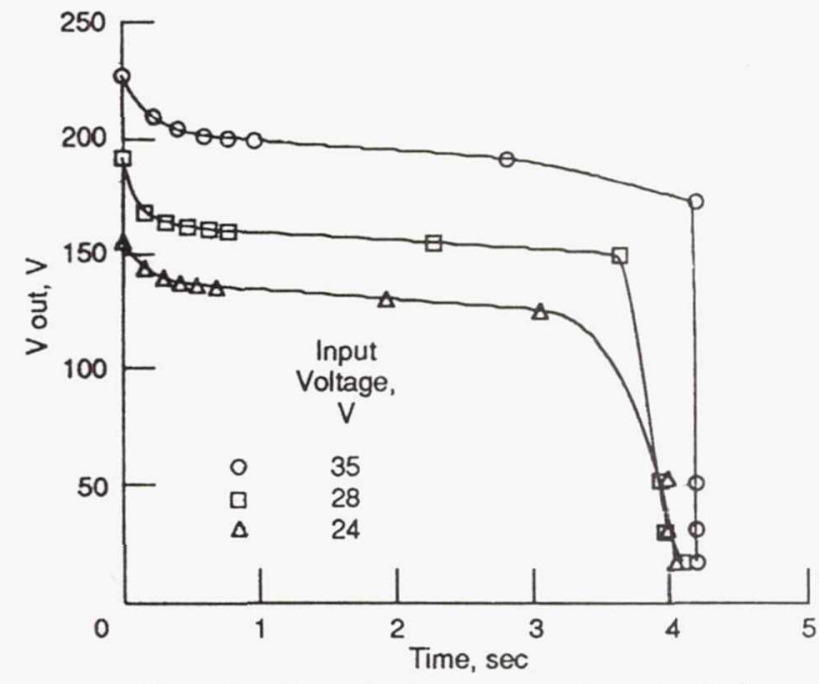

Figure 8.- Operational out put envelopes for the low power PPU for various input voltages.

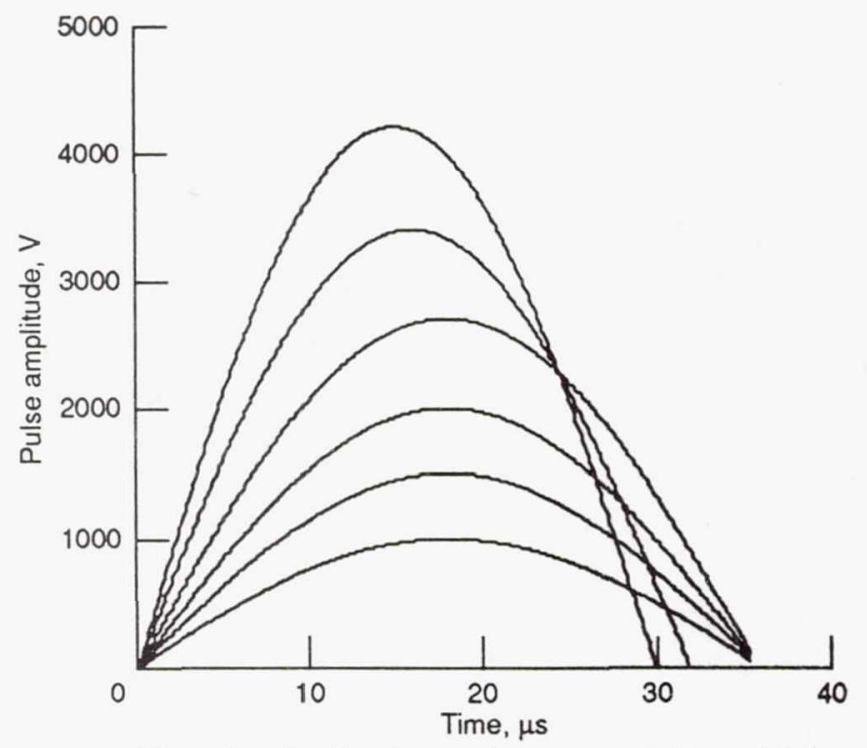

Figure 9.-Family of start pulses generated by variable energy start circuit. Amplitude increases with inductor charge time. 


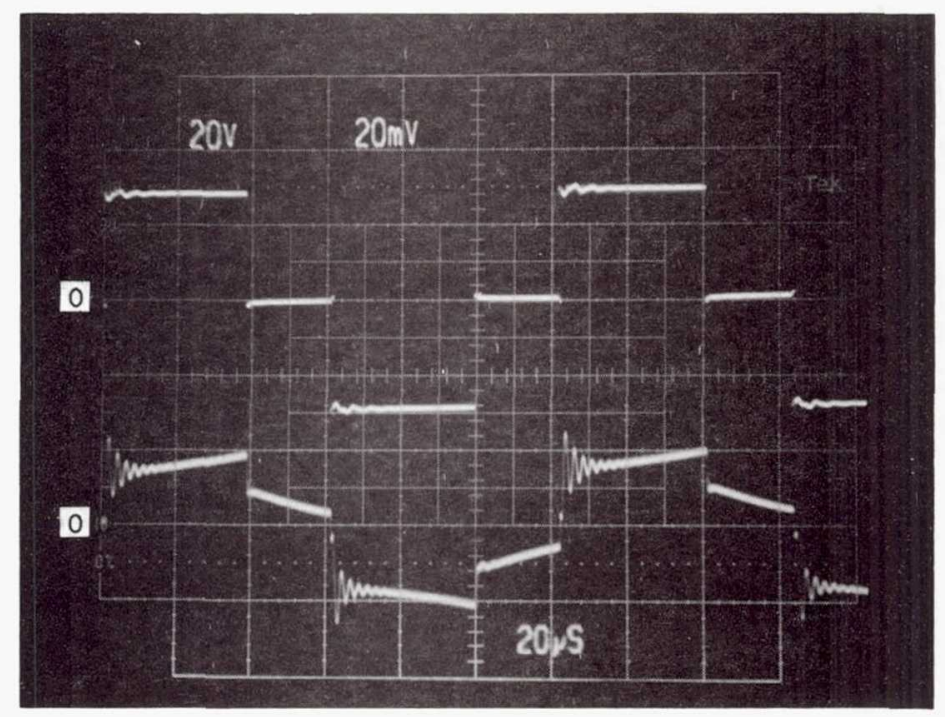

Figure 10.- Primary voltage and current waveforms for the low power arcjet power processor. Upper trace: primary voltage $20 \mathrm{~V} / d i v$. Lower trace: primary current, 20A/div. Horizontal scale: $20 \mu \mathrm{s} / \mathrm{div}$.

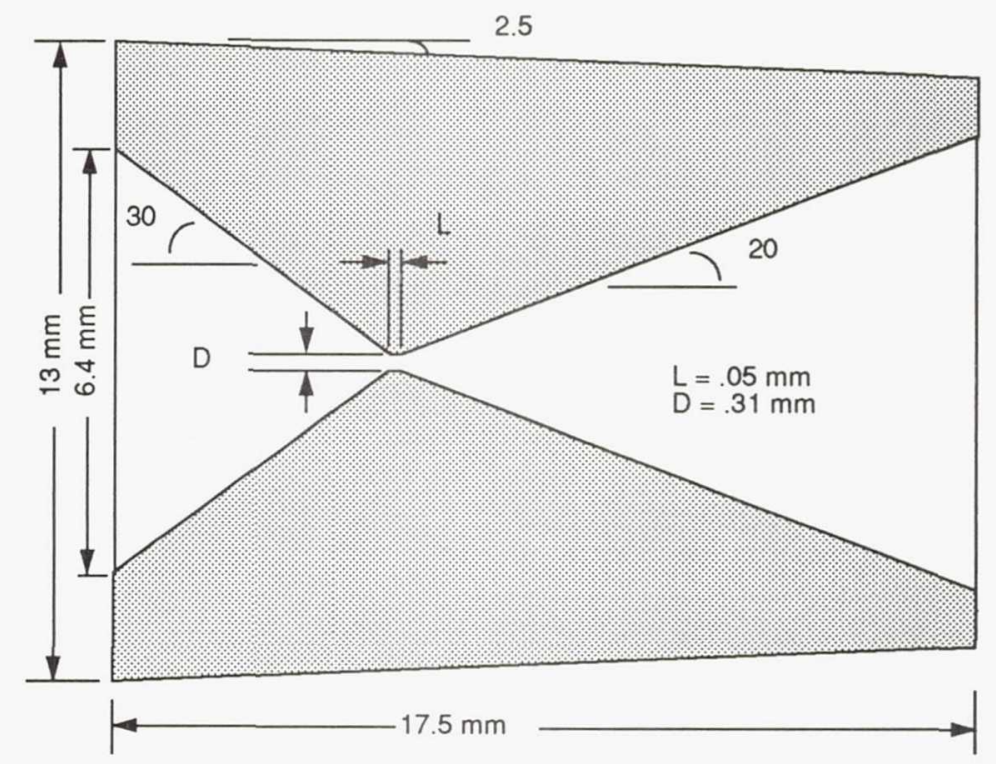

Figure 11.- Low power arcjet nozzle anode insert. 


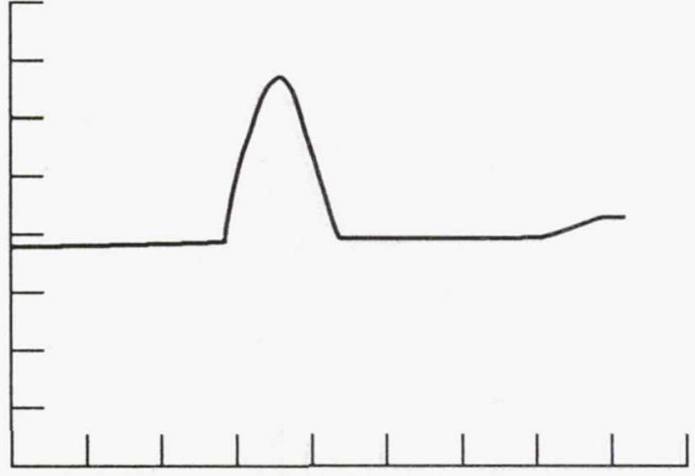

(a) Open circuit starting pulse. Vertical scale: $1 \mathrm{kV} / \mathrm{div}$; Horizontal scale: $25 \mu \mathrm{s} / \mathrm{div}$.

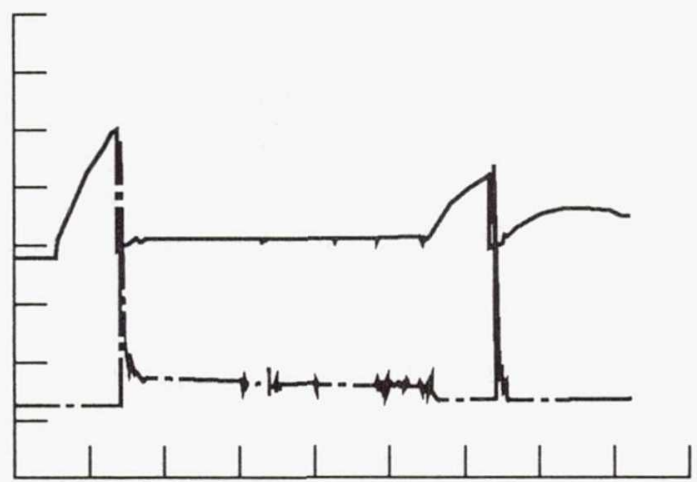

(c) Gas breakdown to arc mode showing double breakdown. Vertical scale: $1 \mathrm{kV} / \mathrm{div}$, aA/div; Horizontal scale: $12.5 \mu \mathrm{s} / \mathrm{div}$.

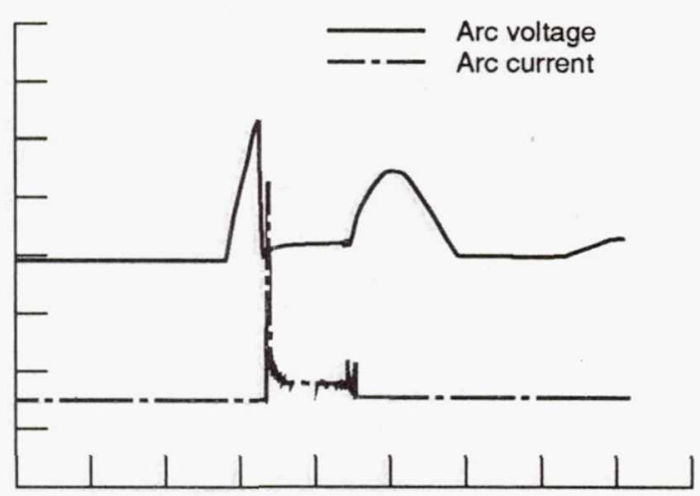

(b) Gas breakdown to arc mode. Vertical scale: $1 \mathrm{kV} / \mathrm{div}$, 2 Avdiv; Horizontal scale: $25 \mu \mathrm{s} /$ div.

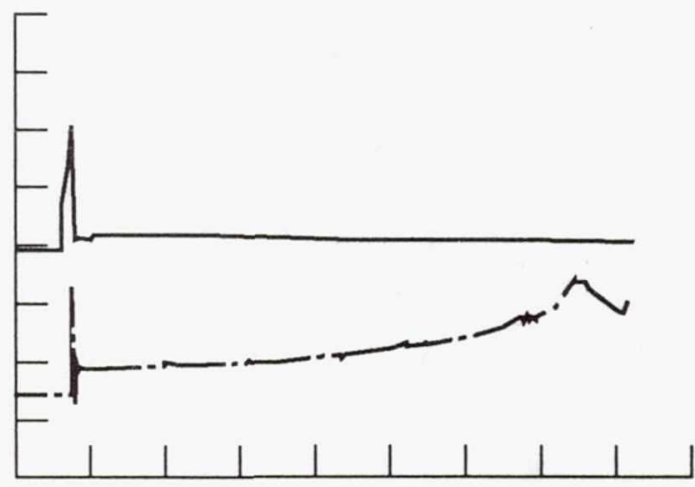

(d) Open circuit starting pulse. Vertical scale: $1 \mathrm{kV} / \mathrm{div}$, 2A/div; Horizontal scale: $50 \mu \mathrm{s} / \mathrm{div}$.

Figure 12.-Arcjet nozzle.

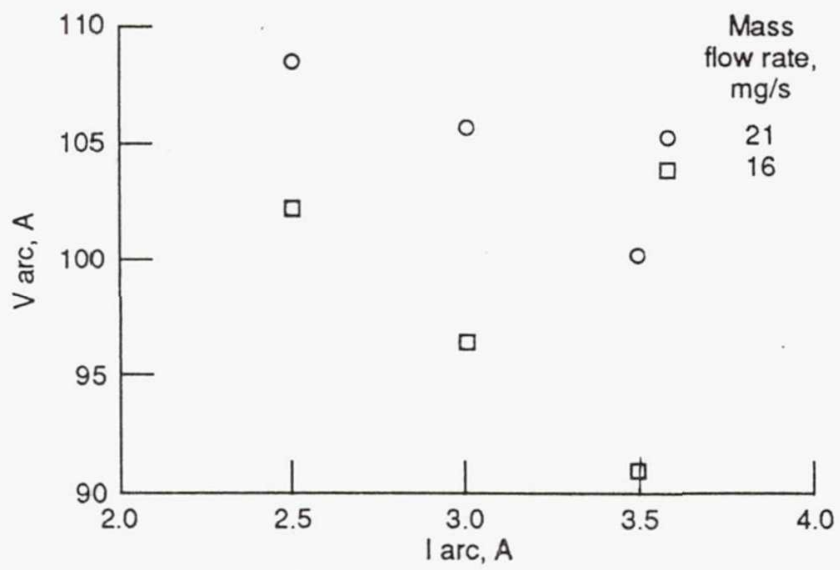

Figure 13. Static V/l curves for a low power arcjet. Constrictor dimensions are $.304 \mathrm{~mm} \mathrm{~d} \times .051 \mathrm{~mm} 1$. 


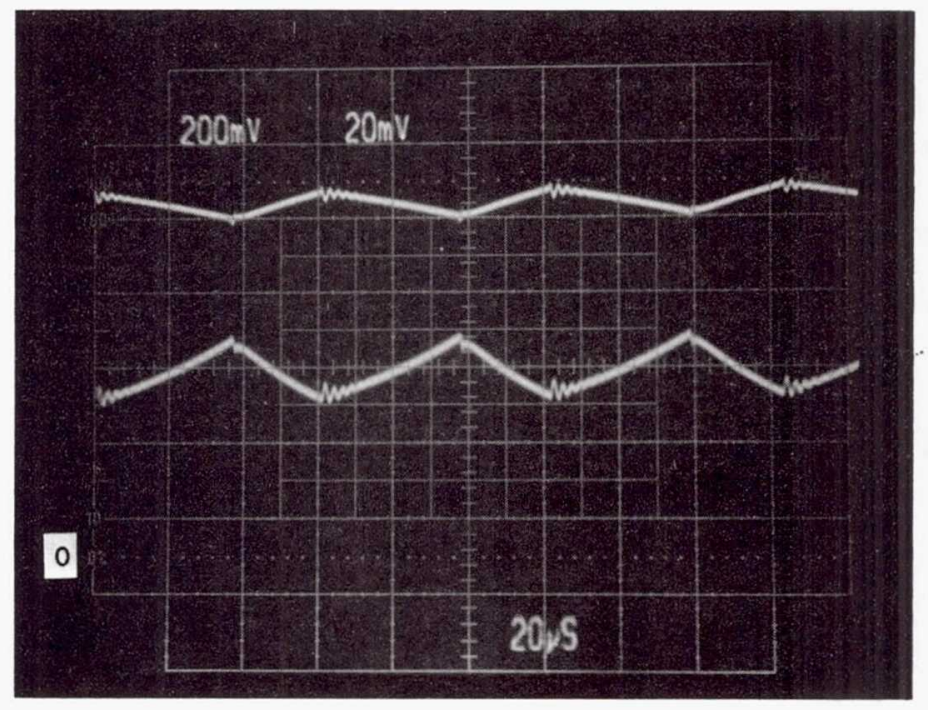

Figure 14.- Output voltage and current waveforms for steady state operation with an arcjet load, upper trace: arc voltage 20V/div., arc current 1 Addiv.

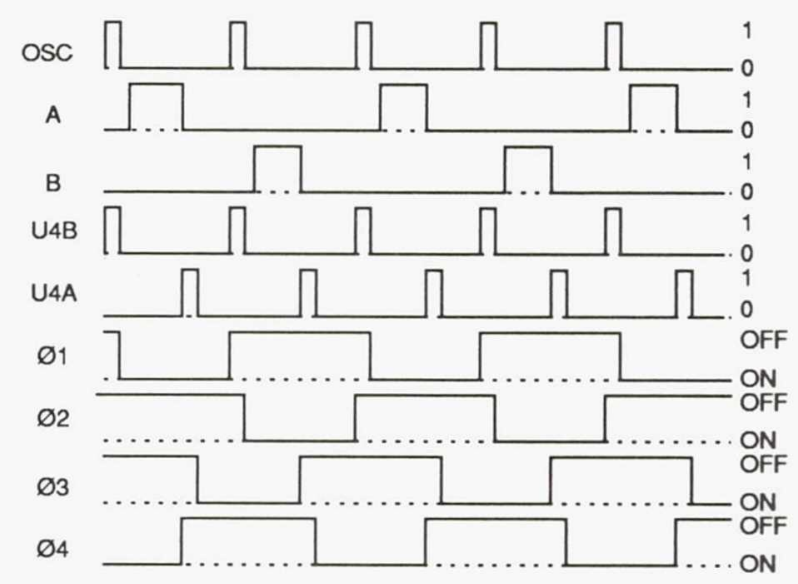

Figure A1.-Pulse width modulation to phase shift converter circuit logic diagram. 


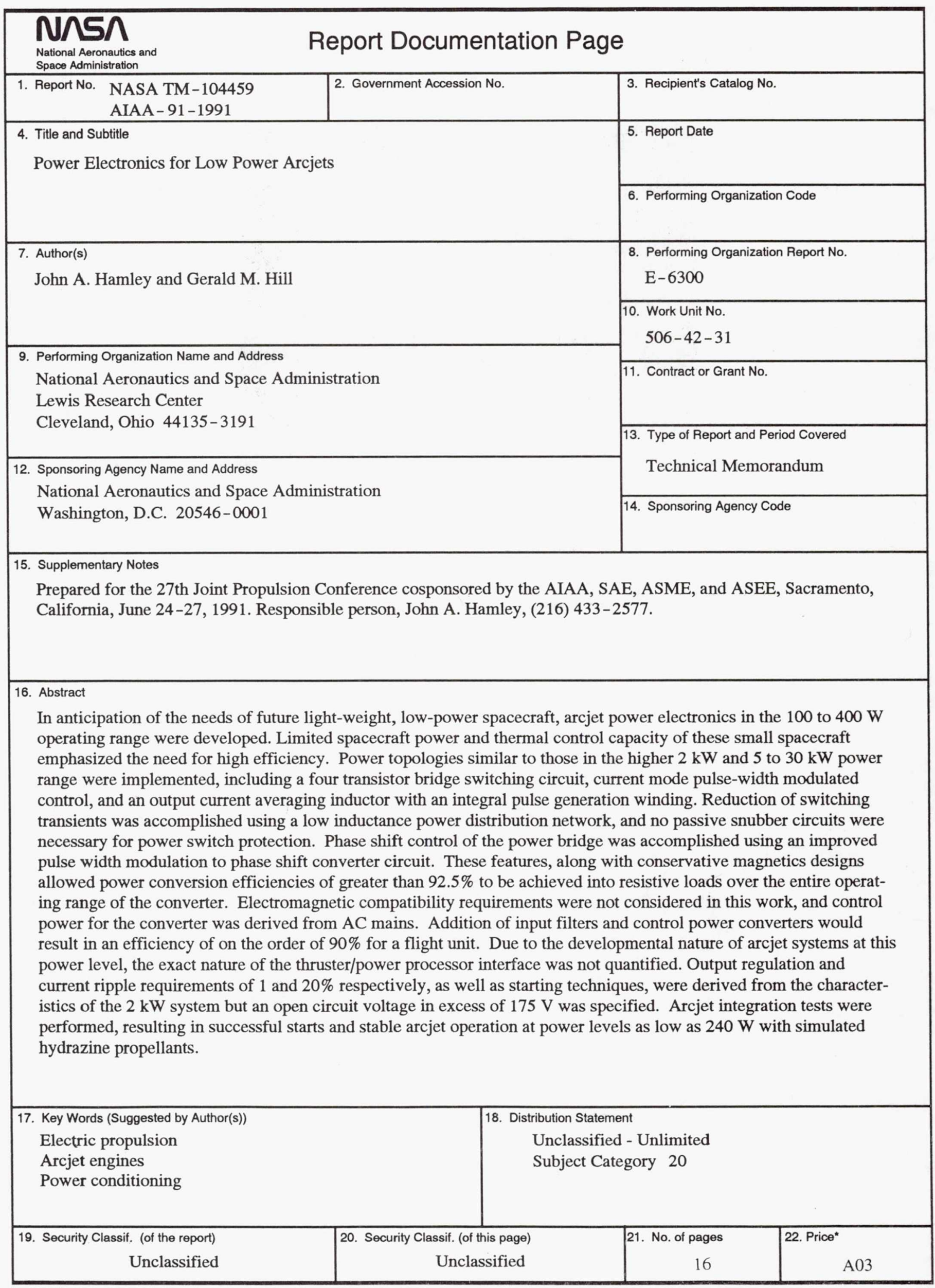

